\title{
Revitalizing a Student Organization by Applying Transformational Leadership
}

\author{
Julianna Ewell \\ Undergraduate Student \\ Texas A\&M University
}

\begin{abstract}
This case study examines the application of a known leadership theory, Transformational Leadership, within the student organization at a large U.S. university, during a time period when the organization was undergoing significant leadership turnover and impending dissolution of the club. By applying principles of Transformational Leadership, the organization's President was able to foster a cohesive team of organization officers, to grow the organization membership population, and to achieve organization goals. As this phenomenon under study is highly context-dependent, the case study approach will better demonstrate the theory's effects within these specific circumstances than will an esoteric, quantitative research approach. Let the findings from this case be an example for other student organizations and leadership teams to generate results with a leadership theory.
\end{abstract}

\section{Introduction}

This single case study examines a student's application of Transformational Leadership theory within a student organization, henceforth referred to as "Aggie Habitat", during a tumultuous year for the group. Instructions about qualitative research reports suggest using a case study approach when the author believes contextual conditions are relevant to the studied phenomenon or when there are not clear boundaries between the studied phenomenon and the context it is in (Baxter, 2008). This case was dependent on a multitude of variables, such as preceding circumstances, the individuals involved, the timeframe, and the environment of the university. This project was a study of social science in which variables and results could not be isolated objectively; the entire situation must be analyzed as a whole to be properly understood. Bent Flyvbjerg (2006) describes the importance of researchers studying in-depth cases, especially for social sciences. Flyvberg (2006) posits the wealth of details of real-life case study situations is important for the researcher to form a nuanced view of reality - that human behavior cannot be meaningfully understood as rule-governed theories - and to help the researcher develop skills to do effective research (Flyvberg, 2006). Further, this study fits Robert Yin's exploratory case categorization, as "the intervention being evaluated has no clear, single set of outcomes" (Baxter, 2008, p. 548).

This real-life example of an effective leadership style can benefit other student leaders and group-management situations. Much of the research published on Transformational Leadership describes either its theoretical components or compares its efficacy to that of other styles. Yet these conceptual articles are limited because, "In a teaching situation, well-chosen case studies can help the student achieve competence, whereas context-independent facts and rules will bring the student just to the beginner's level" (Flyvberg, 2006, p. 222). The setting 
within Aggie Habitat reveals intricacies of team dynamics, so is a sound example of the theory's sweeping effects.

\section{Literature Review}

Transformational Leadership. Transformational Leadership ("TL") is a leadership theory where a leader causes change in individuals or a group (Langston.edu, 2010; Stevens, 2013). Leaders using this approach have the ability to motivate others, "to want to change, to improve, and to be led" (Hall, 2002). Bernie Bass set the foundations of TL in his book Leadership and Performance Beyond Expectations ("LPBE"), which initiated a cascade of research into an entire field of leadership theories that Bass continued to investigate (Yammarino, 1993). LPBE laid the groundwork for nearly 40 scholarly works written in the decade following Bass's publication. These studies generally contend that, "individuals who exhibited transformational leadership were more effective leaders with better work outcomes" (Hall, 2002).

Bass details the importance of TL in his article From Transactional to Transformational Leadership: Learning to Share the Vision (Bass, 1990). Here, Bass states the downsides of Transactional Leadership, where leaders supply a result for a subordinate's action, rewarding good performance and disciplining poor performance. Yet such transaction's efficacy depends on the leader having control over the rewards and penalties, and on whether the follower actually desires or fears them (Bass, 1990). By contrast, inspiring transformational leaders are more likely seen as "satisfying and effective" by their given followers than are transactional leaders using contingent responses (Bass, 1990, p. 21).

Four Factors are postulated in Bass's TL, namely, idealized influence, inspirational motivation, intellectual stimulation, and individual consideration (Langston.edu, 2010; Hall, 2002). However, researchers Wang and Howell (2010) argue transformational leaders should use different behaviors in different situations to best motivate individual followers while simultaneously motivating the collective group, hence their positing of more detailed Dimensions. Dimensions of TL that empower individual followers are the leader's behavior to communicate high expectations, develop the followers, intellectually stimulate, and provide personal recognition. Dimensions of TL that empower the group as a whole are the leader's actions to emphasize group identity, communicate a group vision, and focus on team-building (Wang \& Howell, 2010).

Idealized influence involves the leader serving as a good role model (Hall, 2002). According to Bass (1990), a leader's influential charisma inspires followers because they desire to emulate the leader and have high levels of trust and confidence in them. Further, TL leaders will inspire their followers by providing a sense of mission, instilling pride, and building trust among the followers (Bass, 1990, p. 22). Trust and respect are integral to any relationship, and without these traits, followers can spout antagonizing criticism on the leader.

Inspirational motivation has the leader motivating the group to commit to a shared vision (Hall, 2002). Inspired individuals are excited to accomplish lofty goals, while lack of inspiration is likely to breed mediocre effort and achievement. Bass asserts uniting the group behind a 
mission through communicating high expectations, using symbols, and expressing important ideas in simple ways (Bass, 1990).

Intellectual stimulation has the leader encourage creativity by challenging the status quo (Hall, 2002). TL leaders show followers, "new ways of looking at old problems," and how to find creative and rational solutions for difficulties (Bass, 1990, p. 21). Exemplifying and teaching problem-solving skills gives followers the ability and confidence to tackle challenges, so they will not be deterred from the organization when difficulties arise.

Individual consideration has the leader acting as a coach to the group's individuals (Hall, 2002). While the other factors focus on the group as a whole, this factor promotes the leader paying attention to each of the followers, recognizing unique strengths, weaknesses, ideas, and emotions. Effective TL leaders "act as mentors to those who need help to grow and develop" (Bass, 1990, p. 21).

There are no exact methods required to apply TL, as it can incorporate all or some of the components, each to varying degrees (Hall, 2002). Leaders can implement TL to suit their circumstances and personal styles. The theory is broad and ultimately depends on whether the leader is able to motivate change in other people, enhancing group performance at least in some way (Hall, 2002).

\section{Description of Application}

Background of this organization is provided to this case study, followed by framing the organizational issues that would likely benefit from TL theory.

Organization Background. Aggie Habitat is the Texas A\&M University campus chapter of Habitat for Humanity International ("HFHI"). The student-run organization was founded in 1992, and has since established a sound reputation in the local community. The 2012-2013 school year was one of the group's most successful. That year's officers were professional and organized, there were approximately 200 active members, a key annual fundraiser generated its highest income to-date, and the organization funded construction for two houses.

However, the following 2013-2014 year brought numerous challenges, significantly harming the organization. The membership count was obliterated at the first informational meeting; a conflict with room reservations caused this vital meeting to be held outside, frazzled officers shouting haphazard speeches to a judgmental audience. Additionally, within the first month of the year, 4 of the 14 officers quit Aggie Habitat, and the group struggled to recover. That year's group suffered from weak central leadership; the President was occupied with applying to medical school, and the other officers did not shoulder necessary responsibility. Aggie Habitat fell into a downward spiral during the year, unable to fundraise construction of a house, and less than 20 general members attended the year's final meeting. Those few attendees were implored to become the succeeding officers, despite all but two having only become members that semester, and so had little knowledge of the organization. All of the 2013-2014 officers were leaving the group, except one, and the faculty advisor was stepping down as well. Thus, with an army of brand-new officers and scars from a difficult year, the lone returning 
officer - the new President - assumed responsibility for restoring Aggie Habitat.

Organizational Issues. The following methods describe how the President applied TL in Aggie Habitat. Note, there is discernable overlap in the Four Factors and the Dimensions of TL; thus, many of the initiatives undertaken herein can be classified by multiple categories. Therefore, a chronological description of methods is more suitable than a categorical listing.

The specific leadership goals discussed in this case study were to increase Aggie Habitat's membership and to improve member retention. TL's usefulness herein is epitomized by Bass's (1990) declaration that, "Problems, rapid changes, and uncertainties call for a flexible organization with determined leaders who can inspire employees to participate enthusiastically in team efforts and share in organizational goals" (p. 31).

The President devoted the majority of her TL efforts to the incoming officers, as they were inexperienced and their competency was necessary for the club's success. By building a strong unit of leaders at the top, benefits of TL would theoretically flow throughout the organization. The first step was to build a foundation of teamwork. Before the fall semester, she organized an officer retreat for these new students to officially meet one another and overcome inevitable social awkwardness. As experienced in numerous group projects during school, there is usually some discomfort in a new group environment. Quickly conquering this tendency helps avoid long-lasting feelings that might inhibit team functionality. This retreat was also the first time the President would visibly be this group's leader. Thus, she attempted balancing charisma and authority to gain the group's respect, embodying idealized influence. At the retreat, attendees began knowing each other on a personal level and bonded by playing interactive lawn games together, initiating the President's individual consideration of each person. The retreat also served as a pre-year planning meeting. Explaining Aggie Habitat's troubled circumstances would help unite the group by providing a common goal or vision, as dictated in TL theory (Stevens, 2013) for the inspirational motivation factor. By identifying the diminished membership as a need for damage control, the officers were ready to approach the problem with a sense of urgency. Furthermore, the retreat's purpose correlates with the three group-focused TL Dimensions. Emphasizing group identity is "highlighting shared characteristics among group members and stressing followers' membership in the group," (Wang \& Howell, 2010, p. 1136). Communicating a group vision involves articulating a vision of the group for the future (Wang \& Howell, 2010, p. 1136), fitting Bass' inspirational motivation. Team-building is ensuring the group can cooperate and function together to achieve its goals (Wang \& Howell, 2010, p. 1136). The retreat was the first step taken toward building an Aggie Habitat officer team beyond a collection of individuals.

Secondly, the President scheduled a tour of the local city's Habitat Affiliate office, nicknamed a "Habitour". Here, officers were able to meet the Affiliate staff while driving around local neighborhoods to witness the multitude of Habitat offices and construction sites. The President's intent of the Habitour was to enable the officers to enter their positions knowing the Affiliate as a valuable resource, and to appreciate Aggie Habitat's greater impact off-campus. The students were able to see the range of work done by Aggie Habitat's parent office, and hopefully, each officer would be less hesitant when needing to communicate with the Affiliate via email or phone in the future, having already met the staff. The Habitour was the most 
defined event of intellectual stimulation for the officer group, though numerous smaller cases of problem-solving occurred throughout the year.

Moreover, ensuring Aggie Habitat could exist into the future required developing the officers as strong leaders themselves. Initially, the President was the only person with detailed knowledge of each position's duties, yet she emphasized individual consideration to develop her teammates into independent leaders. All officers would need to be proficient and confident in their roles, so it was important to practice effective delegation techniques. Steven Covey emphasizes the downsides of the micromanaging by comparing delegation types. Gofer delegation does not leverage the manager's time nor does it teach the subordinate how to achieve on his own. Stewardship delegation is beneficial because it makes the subordinate responsible for results, but lets them choose the method (Covey, 1989). Tasks do not require completion by one exact method; what matters is the job being accomplished and team members learning to be effective for the future.

Increasing Membership. The previous year was a cautionary example of failures when attracting new members, and the President prioritized avoiding those pitfalls. She stressed to her team the importance of making good first impressions at the annual student center open house event, wherein thousands of students flock to discover student groups they can join.

The open house tells the massive student population Aggie Habitat exists, but it is the first meeting of the fall semester, the informational meeting, that fully persuades new members to join, solidifying perception of the organization. The President was to be the primary speaker at the informational, as she had the most experience managing the organization. In the past, the main speech has mostly summarized the group's annual activities and regulations. However, the President decided to employ TL in the presentation to better impact the one-time audience. TL stipulates to motivate followers to desire a shared goal and empower them to take ownership of the process (Stevens, 2013). The officers were united by inspirational motivation at the retreat, so this factor was expanded to the mass of potential members by providing them a shared purpose as well.

The President's overhauled speech informed the audience why Aggie Habitat is an organization. Her strategic presentation conveyed significance of substandard housing problems in the world, that HFHI's efforts effectively alleviate the problem, and how Aggie Habitat helps improve peoples' lives. She cited statistics, displayed pictures of poverty housing, and had rehearsed numerous times in order to convey confidence, applying idealized influence. The goal was to convince everyone at the meeting - prospective members as well as officers - that HFHI is a worthy cause and the campus chapter is a fantastic way to help the community. Transformational leaders motivate people, and this speech was key to instilling passion in Aggie Habitat's contributors.

Member Retention. Attracting new members continues throughout each school year via word of mouth and positive press, but member retention is frequently a struggle. Aggie Habitat touts the phrase, "You get out of it what you put into it," so students are not required to attend events, leading to sparse attendance. Conscious of this, the entire officer group strove to keep members engaged at general meetings. They implemented various group games, guest speakers 
from the Affiliate and homeowners, restaurant fundraising profit-shares, and an intramural sports team. Similar to the factors of idealized influence and intellectual stimulation, these small-group games were intended to develop friendships and team skills among the members. While individuals might enjoy an activity in itself, friendships could evolve among students who collaborated in construction games, puzzles, or scavenger hunts. The meeting activities and the officers' personal socializing with general members should foster continuing interest in the organization.

\section{Outcomes and Reflections}

TL theory was applied in numerous ways throughout this case study, and notable effects are analyzed herein. Evaluations are discussed regarding strengthening the officer group, potential further development using TL, impacts to membership size and retention.

Building a Leadership Foundation within the Officer Group. TL methods intended to bolster Aggie Habitat's 2014-2015 officer group showed both immediate and long-term results. The retreat was successful since it established the desired team foundation on which the officers could build throughout the year. Any collective social discomfort was a source of bonding and built trust among the group, echoing individual consideration. By discussing Aggie Habitat's annual events and goals, the new officers oriented their intentions to achieve group successes.

The Habitour was successful and in alignment with TL. TL leaders provide a shared vision and help subordinates feel an ownership in their work (Stevens, 2013). All of the officers took interest in the Affiliate's work during the Habitour, absorbing the sights and asking questions. The tour exhibited local low-income neighborhoods where other students might otherwise never see. Witnessing the Affiliate's work beyond Aggie Habitat's involvement exemplified how the student organization is only a part of a greater cause. Moreover, there appeared to be little hesitation by the officers during the year when needing to correspond with Affiliate staff. The early face-to-face meetings with the staff may have prevented potential hindered communications.

TL appeared useful in developing the officers into quality individual leaders. The four individual-focused TL traits previously denoted are behaviors meant to empower individual followers to develop their full potentials, enhance abilities and skills, and improve self-efficacy and self-esteem (Wang \& Howell, 2010). Communicating high expectations involves demonstrating "the leader's expectations for excellence, quality, and high performance by followers" (Wang \& Howell, 2010, p. 1135). The President did not explicitly state expected behavior or quality standards of the officers, but instead shared implicit expectations of achievement, via her attitudes and discussions at the weekly officer-only meetings. These meetings frequently included her guiding group reflection on organization activities, noting related strengths and weaknesses of the events, but not of the team members themselves. Performance reviews of each officer were intended to occur twice per semester, but such process had not been implemented in the year under study. 
Follower development is "behavior that enhances followers' skills and abilities" (Wang \& Howell, 2010, p. 1135), fitting Bass' individualized consideration characteristic, paying attention to individuals' needs for achievement. Transformational leaders should serve as coaches, teaching subordinates to grow through constructive feedback and delegation. Similarly, intellectual stimulation encourages followers to be creative critical thinkers. These two Dimensions were accomplished during the year via effective delegation and by allowing each officer leniency in performing his tasks, rather than forcing him to prescribe existing methods.

The fourth Dimension, personal recognition, is acknowledging followers for their good work, and stems from Bass' contingent reward component (Wang \& Howell, 2010). Acknowledgements can range from "impersonal economic exchanges" to "emotional exchanges" (Wang \& Howell, 2010, p. 1136), as both forms can transform the individual's psychology. The President consciously gave positive reinforcement to the officers throughout the year, hoping to keep the group motivated. Some lethargy was observed over the winter break, but this is an understandable rest period for college students. Perhaps the continual recognition helped rekindle commitment in the spring semester.

Continued TL Development. Becoming a transformational leader is an adoptive and continuing process. The President was aware that other officers might perceive her as dictatorial, since she had years more experience. The officers might also have perceived TL methods as manipulative, depending on presentation of recognitions and motivations. Dennis Tourish highlights potential detriments of TL, stating transformational leaders can erroneously be given unbounded power if they are believed to have inherently good intentions, and TL ideas are parallel to those in corrupt corporations and cults (de Villiers, 2014). Tourish warns "one of the most malignant and commonplace symptoms of leadership's dark side is the way in which dissent from powerful leaders is constrained and often eliminated", and so, "Inevitable debates and disagreements on strategy are best brought into the open, where they can be engaged by leaders, rather than repressed, denied or ignored" (as cited in de Villiers, 2014). This year's officer group generally circumvented such pitfalls since the President deliberately encouraged open discussions and seeing multiple viewpoints on decisions. This approach aided making decisions as a team, and has notably spurred individual team members to speak their minds; a couple of officers who had looked shy at the beginning of the year had become confident in sharing opinions at group meetings, even if in opposition to the President or to the majority.

TL is not always considered risky or malicious. Multiple studies have found TL behaviors in leaders have positive effects on follower well-being and performance (Mason, 2014). Some researchers suggest leaders or managers should take training programs specific to TL (Mason, 2014). In theory, a transformational leader should have strong belief in his abilities to act as a good leader, and have high self-efficacy to rally an organization around a shared vision and confidently challenge tradition (Mason, 2014). John Sosik further states perspective taking helps leaders articulate visions that appeal to followers, stimulate intellectual engagement in followers, and be aware of followers possibly each having different viewpoints (as cited in Mason, 2014). High positive affect in leaders can drive behavior changes, so a leader with a better mood can better utilize TL concepts, such as building strong relationships with team members (Mason, 2014). 
These three psychological attribute theories showed merit during this case study, personally for the President and for the Aggie Habitat officers. The group was willing to assume more challenging projects and exert more effort to their roles later in the year, once they gained confidence in their capabilities and became friends. The President worked to consider the perspectives of her fellow officers, especially when dissenting opinions arose. She regularly sought feedback on her ideas and management skills from individual officers, feedback on the club's activities from its members, and input on Aggie Habitat's progress from the Affiliate. This 360-degree feedback approach correlates to perspective taking since it enables the leader to make ongoing self-corrections by raising awareness of how her behavior is being perceived, and how her behaviors might need modification to achieve desired outcomes (Mason, 2014).

Increasing Membership. Certain of the actions described above were meant to impact Aggie Habitat in the long term, but they already showed effects during that year, including an increase in membership. The open house spread awareness of Aggie Habitat's presence on campus, but the primary cause of membership growth was the informational presentation.

TL depends on the leader being a visionary; he should adopt a vision, recruit followers to adopt it, and provide direction to accomplish it (Stevens, 2013). The President thus chose to incorporate the core concept of Simon Sinek's Golden Circle in her speech, being that 'people do not buy what you do, they buy why you do it' (Sinek, 2009). The Golden Circle's "why" layer educated about the proliferation and societal harms of poverty housing. The next layer of "how" explained how HFHI works to alleviate the problem. The third layer of "what" described what Aggie Habitat members do to help HFHI. In this order, the audience was motivated with rational and possibly emotional arguments to join Aggie Habitat's cause.

Official membership count is measured as the number of students who pay dues to the organization each semester. The number of paid members for the 2014 spring semester was undocumented, but fewer than 40 students were participating in the organization at that time. By the end of the 2014 fall semester, the organization had grown to approximately 100 paid members. The speech appeared to have the requisite effect, and the membership continued growing after a second informational in the spring, approximating 175 members in April 2015.

Member Retention. As member retention must be evaluated over time, the project's full effectiveness could not be determined after only one year. As of April 2015, the total number of paid members was drastically higher than the number of members who attend general meetings. The more recent meetings had 20 to 40 students in attendance, including approximately 10 to 15 students who attend the majority of the organization's events. The meetings' activities appear to have socially connected these die-hard students with the club. They feel engaged at events and are likely to remain involved with this network. However, since the number of year-end attendees was significantly less than that of paid members, the organization still struggled with retaining members' physical presence.

Member interest in student organizations is difficult to measure overall because so many factors influence participants. Regardless of desire levels, students may not be able to attend meetings if they have scheduling conflicts with other organizations, classes, or exams. College students may prioritize studying, socializing, and relaxation above extracurricular involvement. 
Additionally, this university campus is large and the majority of students live off-campus, perhaps miles away from the meeting and event locations, so it might be tedious for students to coordinate transportation. These are only a few variables that could have hindered member retention, but they are not unique to Aggie Habitat.

More definitive appraisals of improved member retention are measuring how many members return or join in subsequent semesters, and measuring which students will pursue a future officer position. If the current officers and current members wish to serve as officers again rather than leave the organization, they likely feel engaged enough with the organization to remain involved, especially in a dedicated capacity. Such measurement corroborates the increase in general membership because new officers are committing to be involved in advance, suggesting a more-than-temporary interest in the organization. Elections for the new group of officers took place at the end of April 2015. Each of the 2014-2015 officers - besides the two who were graduating - had applied to remain as officers, and general members had also submitted applications. Such participation is a testament to the extent of devotion and competence the group had developed.

The 2015 elections introduced multiple new officers, and the following 2016 elections added even more newcomers. The returning officers have continued implementing certain TL manifestations, despite not knowing the about the underlying theory per se. The original officers still prioritize member-interactive activities at meetings, and the Golden Circle-styled informational speeches are now customary. This sustained effectiveness and continued use of the methods, even without instruction of the theory to the continuing officers, argues for TL as an effective leadership technique.

One of the 2014-2015 officers wrote upward feedback to the President regarding the year under study. She addressed the President, "Overall, your leadership pulled 13 new officers into a well oiled machine. You made all of us confident enough to want to be a part of the organization again and try to continue to make it better," (personal communication, April 28, 2017). This heartfelt declaration summarizes the genuine effectiveness of TL.

\section{Conclusion and Recommendations}

The President applied TL through various methods to increase Aggie Habitat's membership and improve its member retention. She strove to inspire potential members by preaching Habitat's noble purpose. Her informational presentations were integral to revitalizing the organization's membership. Membership retention may not have been a clear success, but this factor may be better evaluated in future semesters. The President also used TL to overcome running the organization with inexperienced officers. Adhering to TL, she first assessed the group's starting condition then shaped the officers into a well-functioning team. She utilized the Four Factors (1990) and considered Dimensions (2010) when applying methods of leading by example, managing with discussion instead of authoritarian dictation, connecting with officers on a personal level, and delegating effectively.

Further extent of the theory's impact could be evaluated if subsequent officers preferably with the same leadership group and some overlap of general members - were to 
employ either TL or a different leadership style; then the results of the year under study could be compared to those of subsequent years'. While TL has already demonstrated practicability, future investigation and comparison studies could reveal more insights. Student leaders seeking to strengthen their group's central leadership or their personal leadership approach should consider this case's techniques and outcomes. Applying TL has helped strengthen Aggie Habitat to endure into the future.

\section{References}

Bass, B. M. (1990, Winter). From transactional to transformational leadership: learning to share the vision. Organizational Dynamics, 18(3), 19-31. Elsevier. DOI: 10.1016/00902616(90)90061-S

Baxter, P., \& Jack, S. (2008). Qualitative Case Study Methodology: Study Design and Implementation for Novice Researchers. The Qualitative Report, 13(4), 544-559. Retrieved from http://nsuworks.nova.edu/tqr/vol13/iss4/2

Covey, Stephen. (1989). The Seven Habits of Highly Effective People. New York, NY: Free Press.

de Villiers, Rouxele. (2014). Book essay on "The Dark Side of Transformational Leadership: A Critical Perspective" [Review of the book The Dark Side of Transformational Leadership: A Critical Perspective, by Dennis Tourish]. Journal of Business Research, 67, 2512-2514. DOI:10.1016/j.jbusres.2014.01.006

Flyvbjerg, Bent, (2006). Five misunderstandings about case-study research. Qualitative Inquiry, 12 (2), 219-245. DOI 10.1177/1077800405284363

Hall, John, Johnson, S., Wysocki, A., \& Kepner, K. (2002, June). Transformational leadership: the transformation of managers and associates. University of Florida IFAS Extension. Retrieved from http://edis.ifas.ufl.edu/hr020

Langston.edu. Transformational Leadership. (2010). Retrieved from http://www.langston.edu/sites/default/files/basic-contentfiles/TransformationalLeadership.pdf.

Mason, Claire, Griffin, M., Parker, S. (2014). Transformational leadership development: connecting psychological and behavioral change. Leadership \& Organizational Development Journal, 35 (2), 174-194. DOI: 10.1108/LODJ-05-2012-0063

Sinek, Simon. 2009, September. How great leaders inspire action. TEDxPuget Sound. http://www.ted.com/talks/simon_sinek_how_great_leaders_inspire_action?language=en 
Stevens, Monica. (2013). Transformational Leadership. Kentucky Nurse, 61 (2), 4. http://web.b.ebscohost.com.libezproxy.tamu.edu:2048/ehost/pdfviewer/pdfviewer?sid=7b9afae9-8edb-4d4c-8f74facab3e41398\%40sessionmgr111\&vid=2\&hid=124

Wang, Xiao-Hua (Frank) \& Howell, J. M. (2010). Exploring the dual-level effects of transformational leadership on followers. Journal of Applied Psychology, 95 (6), 11341144. DOI: $10.1037 / \mathrm{a} 0020754$

Yammarino, F. J. (1993). Transforming leadership studies: Bernard Bass' leadership and performance beyond expectations. The Leadership Quarterly, 4 (3-4), 379-382. DOI: $10.1016 / 1048-9843(93) 90043-S$

\section{Author Biography}

Juli Ewell is a graduate of Texas A\&M University, where she served as an active student leader in the university's chapter of Habitat for Humanity. While enrolled, she utilized her leadership experience to complete a University Honors Fellows Distinction and for indoctrination to the Maroon \& White Leadership Fellows Society. 